Article

\title{
Sustainable Renewal Methods of Urban Public Parking Spaces under the Scenario of Shared Autonomous Vehicles (SAV): A Review and a Proposal
}

\author{
Bing Xia ${ }^{1,2,3}$, Jindong $\mathrm{Wu}^{3, *}$, Jiaqi Wang ${ }^{3, *}$, Yitao Fang ${ }^{3}$, Haodi Shen ${ }^{3}$ and Jingli Shen ${ }^{3}$ \\ 1 Center for Balance Architecture, Zhejiang University, Hangzhou 310028, China; 0016217@zju.edu.cn \\ 2 State Key Laboratory of Green Building in Western China, Xian University of Architecture \& Technology, \\ Xian 710055, China \\ 3 College of Civil Engineering and Architecture, Zhejiang University, Hangzhou 310058, China; \\ 3170103421@zju.edu.cn (Y.F.); 3170103594@zju.edu.cn (H.S.); 3170103424@zju.edu.cn (J.S.) \\ * Correspondence: Jindongwu@zju.edu.cn (J.W.); jiaqi-nancy-wang@zju.edu.cn (J.W.)
}

Citation: Xia, B.; Wu, J.; Wang, J.; Fang, Y.; Shen, H.; Shen, J. Sustainable Renewal Methods of Urban Public Parking Spaces under the Scenario of Shared Autonomous Vehicles (SAV): A Review and a Proposal. Sustainability 2021, 13, 3629. https:// doi.org/10.3390/su13073629

Academic Editor: David A. King

Received: 4 February 2021

Accepted: 18 March 2021

Published: 24 March 2021

Publisher's Note: MDPI stays neutral with regard to jurisdictional claims in published maps and institutional affiliations.

Copyright: (c) 2021 by the authors. Licensee MDPI, Basel, Switzerland. This article is an open access article distributed under the terms and conditions of the Creative Commons Attribution (CC BY) license (https:// creativecommons.org/licenses/by/ $4.0 /)$.

\begin{abstract}
Shared autonomous vehicles (SAVs) will be an important force to in reshaping urban morphology. The high operation rate and sharing degree of SAV are considered to result in a great reduction in parking area in future cities. Parking space is now a huge and widely distributed urban stock space type, which is bound to become a major challenge and opportunity for sustainable urban renewal in the digital era. Based on the SAV scenario, this paper reviews the current research on the sustainable renewal of urban public parking spaces, and proposes the four key issues involved: how much to renew (i.e., demand forecast analysis), when to renew (i.e., update time series evaluation), what to renew (i.e., function replacement decision) and how to update (i.e., design empirical research). Furthermore, it puts forward a preliminary idea on, and constructs a research framework for, the sustainable renewal methods of parking space under the SAV scenario. Finally, the theoretical, practical and policy implications of the research on sustainable renewal methods of urban public parking space are discussed. It will have great reference value for the redevelopment and reuse of the urban space types including fragmented, widely distributed and large-scale.
\end{abstract}

Keywords: shared autonomous vehicles (SAVs); public parking space; sustainable renewal; research prospects

\section{Parking Space Renewal under the SAV Scenarios \\ 1.1. Shared Autonomous Vehicle (SAV) Trends}

Autonomous vehicle technology is currently the major development direction of artificial intelligence in the automotive sector [1]. The applications of shared autonomous vehicles (SAVs) will improve social mobility and change our concept of time and distance [2]. With the gradual application of SAVs, urban morphology will evolve in the future, which will create more space in urban road networks [3-5].

Universal access to autonomous vehicles has numerous benefits that include reducing accidents, traffic congestion, commuting time, and carbon emissions [6]. Autonomous vehicle technology would replace commuter driving and bring incremental value to every public transportation user. In addition, autonomous driving technology supports vehicle sharing, addresses multiple challenges in the current vehicle sharing field, and realizes the transition from "people looking for vehicles" to "vehicles looking for people" [7]. With autonomous vehicle technology, vehicle sharing can grow to a large scale without barriers. Further, SAV will increase the use efficiency of vehicles while reducing the ownership of vehicles [8]. In other words, it ensures "making the best use of everything," environmental protection, and public benefit. Therefore, autonomous vehicle technology is widely supported by the governments of various countries [9]. 
Presently, the policies of the autonomous vehicle industry are undergoing steady improvement [10-14]. All groups in society have high expectations as regards this technology's environmental protection and convenience [15-17]. The relevant frontier technologies continue making breakthroughs [18]. All of these have laid a solid foundation for developing the autonomous vehicle industry. It is estimated that fully autonomous vehicle technology could be marketed by $2025[19,20]$. The Institute of Electrical and Electronics Engineers (IEEE) [21] predicts that autonomous vehicles will account for $75 \%$ of all urban motor vehicles by 2040 .

\subsection{Evolution of Parking Spaces in the SAV Era}

The applications of autonomous vehicle technology, characterized by connectivity, sharing, and automation, will significantly impact urban public parking spaces [3,4,22-25]. As static urban traffic, public parking is an indispensable part of modern urban functions [26]. However, in the SAV scenario, a large number of existing parking lots (garages) will be gradually removed or replaced and renovated for other purposes. This mainly manifests in the following ways:

1. The advent of SAVs will reduce the demand for private vehicles. A study by Mitchell et al. $[27,28]$ inferred that private vehicles are unlikely to provide the mobility that citizens need in future mega-cities. A study by the Transportation Research Institute of the University of Michigan [29] demonstrated that vehicle ownership in the US would decrease by approximately $43 \%$ once the usage of autonomous vehicles starts. The rationale behind this is that shared vehicles are more cost-effective to users ( $80 \%$ savings) than ownership of private vehicles. Therefore, when vehicle ownership declines, the corresponding demand for parking will be significantly reduced;

2. The high SAV operation rate and sharing level has triggered a significant reduction in the required amount of parking space. Carlo Ratti, director of MIT's Senseable City Lab, notes that "currently, vehicles in the US are parked approximately $95 \%$ of the time on average." [30] Sebation Thrun, a computer expert at Stanford University and former Google expert on their autonomous vehicle project, said that "once autonomous vehicles become mainstream, only $30 \%$ of the vehicles currently on the road will be needed." [31]. In addition, the operation of each autonomous vehicle can replace $10-30$ operational vehicles [30];

3. SAVs have autonomous parking capacity. Therefore, the demand for parking accessibility will be significantly reduced. However, this can rationalize the use of existing parking resources, effectively relieving the pressure on the parking lots in shopping malls, hotels, stations, and other crowded places, as well as significantly reducing the land area required for surface parking [32]. In addition, with this technology, parking lots will be built in urban fringes or places with low economic efficiency, and the ratio of supporting parking spaces for commercial, residential, and public facility lands will be reduced, thereby optimizing the allocation of land resources [33,34];

4. SAV-specific parking buildings completely differ from traditional parking lots and are more space-efficient. The size and space required per vehicle of SAV parking are smaller than those of traditional vehicle parking, because SAV parking does not need to consider the spacing between vehicles [22]. It also does not need so much traffic lane space for vehicles to move in and out. A study has shown that the reduction in the size of SAV parking spaces can result in a $15 \%$ increase in parking capacity on average [35].

\subsection{Challenges and Opportunities of Sustainable Renewal for Parking Spaces}

Public parking space is an important urban stock space [26,36]. The characteristic spatial composition of public parking space makes its renovation and transformation unique compared to conventional urban renewal projects. These features are as follows:

1. Wide distribution, which majorly impacts sustainable urban development. Urban planning standards in various countries all have corresponding parking allocation 
index requirements for different types of land and buildings [37,38]. As an urban static transportation space system, public parking space is fragmented and evenly distributed near various buildings and public places in the city, rooted in the spatial and functional structural network of the city [39,40]. Its spatial distribution characteristics significantly impact the realization of sustainable urban renewal [41,42];

2. Large total volume, giving it a high potential for social benefits and economic value. According to statistics, $13 \%$ of urban space in the US is currently used to build parking lots [24]. Currently, China has 0.3 vehicles per capita [43]. According to the calculation based on 1:1 parking spaces per vehicle and $20-25 \mathrm{~m}^{2}$ per space [44], the total area of parking space in a city of one million people is equivalent to dozens of large commercial complexes. As such, the transformation and utilization of parking spaces has high potential social and economic value;

3. Multiple types, resulting in greater difficulty and complexity in spatial transformation. Urban public parking spaces are diverse in form, including special space forms, such as under viaducts, on building rooftops, and mechanical three-dimensional parking $[38,45,46]$, as well as the more common underground parking garages, surface parking lots, on-street parking spaces, and stand-alone parking buildings [47]. Different parking spaces vary significantly in size and scale, usage, environmental conditions, ownership composition, etc. [26,45]. This results in substantial challenges in retrofitting spaces.

Therefore, urban public parking spaces are bound to become a crucial challenge, as well as an opportunity in the process of sustainable urban renewal in the future. In view of this, the academic community needs to urgently establish innovative theories and methods. The wide distribution, large volume, and multiple types of urban parking spaces lead to systemic, diachronic, and complex difficulties, respectively, in their renewal and transformation. Hence, new theories should integrate macro-control, meso-synergy, and micro-guidance in a dynamic renewal process. The implementation framework for the spatial renewal of urban systems should reflect the difference in the renewal time and case category. For the sustainable renewal of parking spaces, the new method should be based on its different attributes to determine the time and content of the renovation, and propose targeted design strategies.

Currently, research on the sustainable renewal of urban public parking spaces in the SAV scenario is a practical necessity. Its significance lies in the following:

1. From the social perspective, it synergizes science, technology, and innovation with the evolution of urban morphology to address the needs of social life in a new era;

2. In the economic sense, it harnesses the value of urban stock space, improves urban vitality and quality, and contributes to economic development;

3. From the theoretical perspective, it establishes a methodology for the sustainable renewal of urban parking spaces and expands the theoretical framework for urban design;

4. In the sense of demonstration, conducting empirical design studies and developing demonstration cases can lead the way in future urban renewal.

\subsection{Aims and Innovations of This Research}

The sustainable renewal of urban parking in the SAV scenario is a forward-looking and strategic research topic. The purpose of this paper is to raise this issue and conduct a preliminary analysis for laying the foundations of the theoretical framework for future research. The research problems this paper attempts to address are:

1. In what ways can urban parking space be renewed and what are the corresponding difficulties?

2. What are the deficiencies in the existing theories, methods, and practices concerning parking renewal?

3. Establishing a framework for parking space renewal in the SAV scenario. 
4. What are the theoretical, practical, and policy implications of the proposed renewal method?

The uniqueness of this paper lies in:

1. Proposing the idea and preliminary framework for the sustainable renewal of urban parking space under the SAV scenario.

2. Providing mode references for the redevelopment of fragmented, widely distributed, and large-scale urban spaces.

\section{Research Status of Sustainable Renewal Methods of Parking Spaces}

\subsection{Methods and Theories}

There is a broad international consensus that SAV technology will be a major trigger for future urban transformation [24,48-50]. The general appearance of future cities, including the morphologies of urban roads, parking spaces, and infrastructure, will change drastically with the arrival of SAVs [4,51-53].

Regarding the conception of urban morphology in the SAV era, Chapin et al. [34] envisioned urban streetscape planning in different periods with autonomous vehicle technology. Owing to the efficiency of autonomous vehicles, existing urban roads can be reduced by one or more traffic lanes, which can be used as stop-and-go lanes, sidewalks, or bike lanes. Based on the "safety", "mobility", and "balanced right" principles, the National Association of City Transportation Officials [54] proposed guidelines for the spatial planning of urban streets with autonomous vehicle technology. Wang et al. [55] explored the adaptive change characteristics of urban space and urban functions in the era of autonomous vehicles based on characteristics of autonomous vehicle traffic, benefit matrix, and the prospect of scaling up. Xie Siyuan et al. [33] analyzed the impact of autonomous vehicle technology on street space and proposed principles and strategies for the optimal design of static traffic space. Based on an overview of SAV urban space governance in China and other countries, Zhang et al. [56] took Nanjing as an empirical research object and employed field research and structured interviews to systematically comb the challenges of urban space under the impact of shared vehicles. LYFT (a leading company engaged in SAV), in collaboration with Perkins \& Will Architects, proposed the world's first autonomous vehicle-based street space concept in the Wilshire street block of Los Angeles [57], and completed the design proposal.

Regarding the prediction of the size and distribution of future parking spaces, Zhang et al. [35] adopted a multi-agent simulation model to estimate the potential impact of SAVs on the demand for urban parking, under different system operation scenarios. The results obtained indicated that approximately $90 \%$ of the demand for parking could be eliminated. Another study by Zhang et al. [58] adopted real transportation networks and travel demand origin-destination (OD) matrices to simulate the evolution of the parking system in the city of Atlanta, USA, after the adoption of SAVs. The simulation results indicated that $4.5 \%$ of the parking land in Atlanta can be reduced when 5\% of the traffic trips adopt the SAV model. Recent research by Zhang and Wang [59] analyzed the demand reduction trajectory during the transition period when there is a mix of SAVs, privately owned AVs (PAVs), shared conventional vehicles (SCVs), and conventional private vehicles (CPVs). Bischoff et al. [60] introduced multi-agent technology to simulate the parking search behavior of autonomous vehicles under three different parking strategies (regular parking, parking in designated lots, and empty cruising), and applied the model to a residential area in downtown Berlin for detailed evaluation. Simons et al. [61] investigated the sustainability of downtown parking when autonomous vehicles are present. By reviewing the research of 21 practitioners on SAV applications, they predicted a $20-66 \%$ decrease in the net demand for parking in downtown Cleveland by 2035. They concluded that future vehicle maintenance and parking space demands could be met using existing excessive parking lots at airports or soccer stadia.

Regarding the renewal planning for existing parking lots, Ziegenfuss [62] investigated how to create temporary public places in underutilized parking spaces. Based on the 
environmental characteristics, mixed functional goals, and a zoning regulatory framework, Ziegenfuss analyzed public activities suitable for different types of surface parking lots and discussed methods for implementing the temporary reuse of parking spaces. Xu et al. [63] posited that autonomous vehicle technology would facilitate the functional replacement of parking lots as "ecological units" to link different urban areas, thereby realizing ecological base replacement, patch reconstruction, and ecological network restoration. Simons and Kline [64] presented a method of evaluating the potential of the sustainable reuse of parking buildings. Integrating the basic construction factors of the parking garage, various potential end uses, and the basic requirements of regulation for renewal, they developed a simple analysis method which could identify the most adaptive and sustainable renewal targets for a certain case.

Regarding the SAV parking spaces that need to be reserved, the design of future parking facilities will also change. In contrast with regular parking lots that have only two rows of vehicles per island, future parking lots can stack multiple rows of other vehicles behind each vehicle (Figure 1). Ferreira et al. [65] proposed a novel concept of automated parking, wherein autonomous vehicles move collaboratively using a self-organizing network of vehicles to ensure easy entry and exit despite their dense arrangement. This method saves half the space required by traditional parking methods. Nourinejad et al. [66] further adopted a problem heuristic algorithm to identify the optimal autonomous vehicle space layout design. Their study demonstrated that autonomous vehicle parking can reduce parking spaces by an average of $62 \%$ and an approximate maximum of $87 \%$.
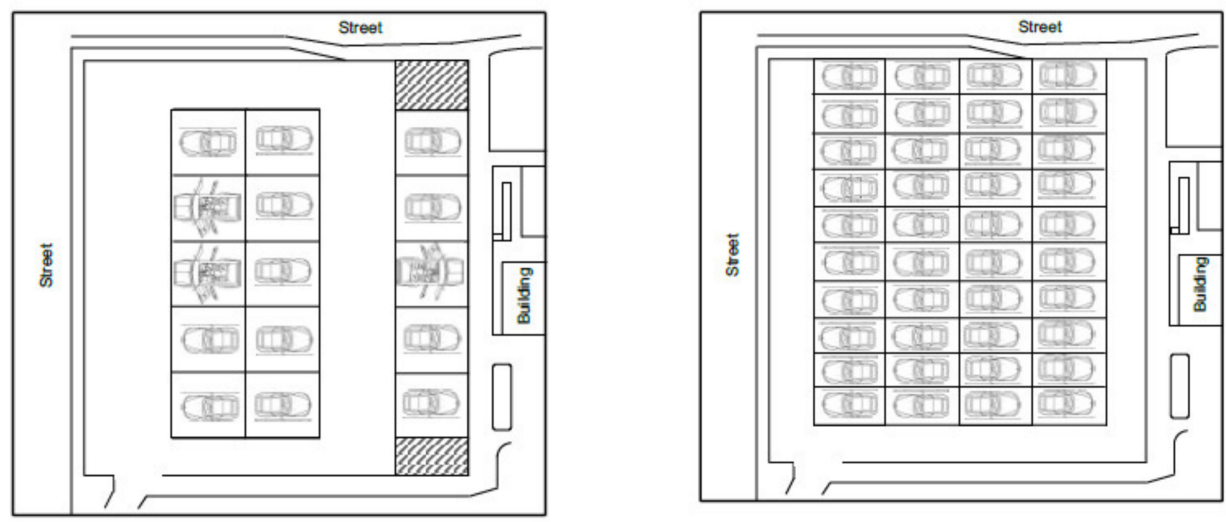

Figure 1. The differences between two parking lot designs: regular parking lot design (left) and autonomous vehicle parking lot design (right), adapted from [66]. Copyright 2021 Elsevier.

\subsection{Practices and Projects}

Currently, there are many cases of parking space renewal or reuse worldwide. However, compared to some well-known constructions, parking space renovations do not attract much attention from the media or academia due to their small scale (single unit) and lack of an iconic external image. However, they usually involve different types of cases, through which researchers and architects have explored and developed different renewal approaches.

Small open-air parking lots and on-street parking spaces are relatively easy to retrofit because of their more dispersed spatial distribution and small scale. The renewal of these spaces is often done on an ad hoc and flexible basis, with government regulations and spontaneous actions by individual property owners [47]. In 2010, the City of San Francisco launched the "51 parklets" project (Figure 2) to explore the elimination of street parking and to revitalize public areas [67]. The conversion of these parking spaces in prime areas into restaurants, retail, and recreational spots has received strong public support with good economic returns. This activity has extended to urban renewal programs in dozens of major cities in North America. For relatively large open-air parking lots, it is possible to create substantial economic value with concentrated functional conversions. For example, 
Square Roots recently created an urban agriculture accelerator in a Brooklyn parking lot, which houses 10 container gardens that can produce up to 500 pounds of fresh agricultural products per week [68].
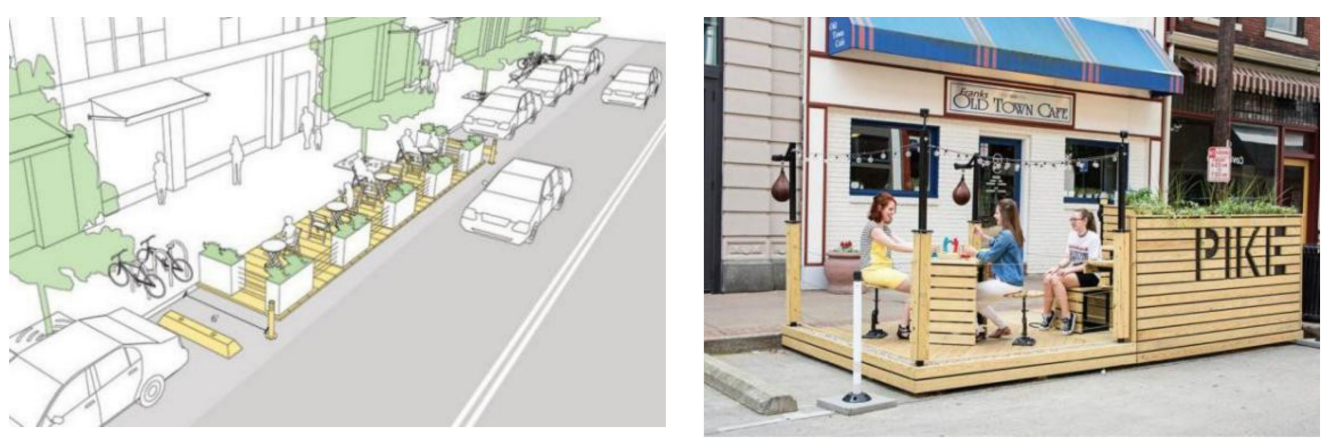

Figure 2. Parking lot conversion: the "51 parklets" project, adapted from [69,70]. Copyright 2021 Island Press (for first figure), 2016 Cincinnati Magazine (for second figure).

The parking garage building is the most common renewal type around the world. Mostly, it is transformed into new functions such as offices, residences, or public culture spaces. For example, the Northwestern University in the US has transformed its 11,000square-foot North Campus parking garage into a student business incubator called "The Garage" [71]. The parking building of the Shanghai Bus Company [72] was converted into a design office space for Tongji University (Figure 3). Knightley's Garage of Broadway was transformed into multi-story apartments [73], and Carl Turner turned the Peckham Levels car park in South East London into an amenity for the arts community [74]. In other retrofit cases, parking function can be replaced with new functions, such as urban threedimensional greenery [75] and cultural outreach facilities with small renewable energy stations [76], etc.
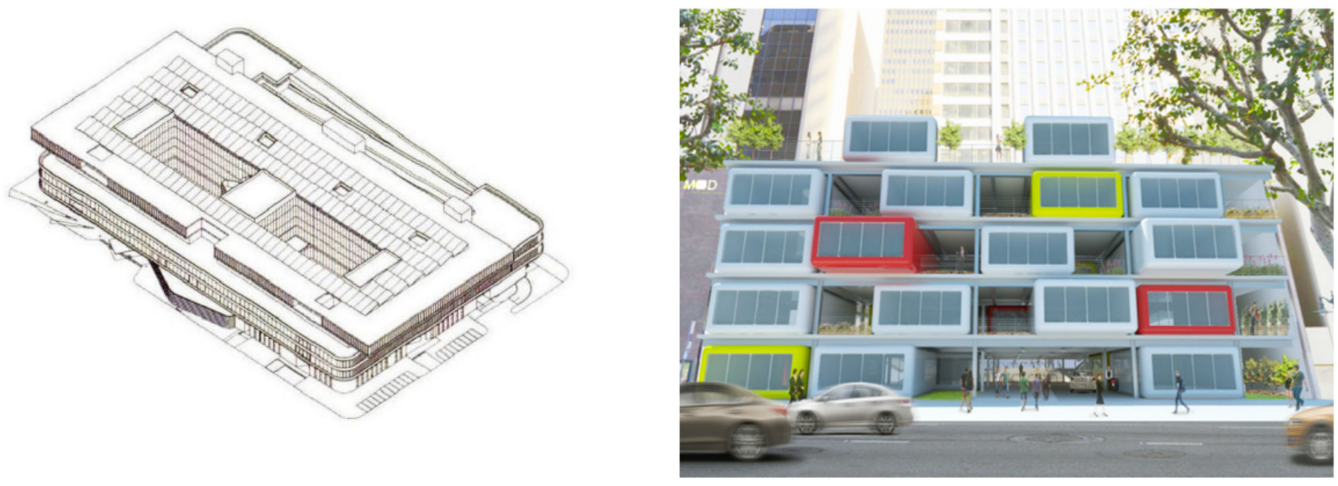

Figure 3. Reconstruction of the parking lot of Shanghai Bus Company (right), "MOD" design concept for parking conversion (left), adapted from [72,77]. Copyright 2021 Zeng Qun (for first figure).

Regarding sustainable issues in retrofitting, Gensler's "MOD" design concept for a cultural center demonstrated how a parking lot can be transformed into a public space for citizens [77]. Their strategies were to raise the floor height to ensure that the floors are leveled between ramps, and to add cavity panels and install easily removable walls and ceilings to increases light and ventilation. The garage was also equipped with appropriate utility connections to prepare for future workspace or retail use. These design strategies were also employed in the $84.51^{\circ}$ Center and Netflix headquarters office building parking spaces [78] (Figure 3). In addition to Gensler, a number of other prominent design firms also actively explored, and ultimately realized, the "future-proofing" concept in parking design. For example, WGI [79] (an American design and professional services firm leading in technology-based solutions for the construction of public infrastructure) designed The 
Wedge, which utilized an adjacent existing parking structure for access, negating the need to build ramps between floors in the new structure. Kasian and 5468796 [80] designed 9th Avenue Parkade, which allows for the future conversion of the space into commercial or residential uses through considerations such as increased floor-to-ceiling heights, and a central atrium space for natural light to penetrate the building. Arrowstreet [74] designed the underground parking space of Boston Parcle K, which envisioned a future doubleheight space that could be created to allow new uses that would engage with street-level retail space. To meet the different functional demands of retrofitting, Dutch designers proposed the use of assembled components (Figure 4) to improve the flexibility of the sustainable renewal of parking structures [81]. Similarly, Gensler is also investigating ways to retrofit old garages with pod-like houses by inserting these residential units into parking structures.
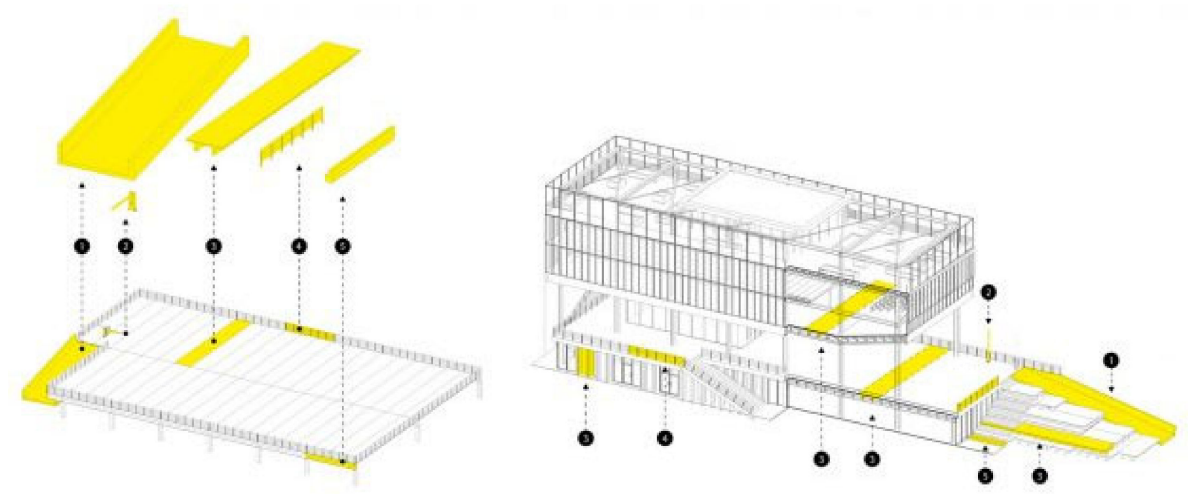

Figure 4. Retrofit garage space with assembled components, adapted from [81].

Mechanical parking devices can also be converted for other functions as lightweight structures. Zeroth et al. [82] proposed a design solution for converting a vehicle lift into a housing pod (Figure 5). The scheme adopts injection-molded panels made of recycled plastic, which are prefabricated off-site, then delivered by truck to the parking lot, and lifted into place using a forklift. In high-density urban areas (e.g., Tokyo, Japan), aboveground parking (parking buildings or on-street parking) accounts for a relatively small part of the total parking in urban planning. Instead, a large number of parking spaces are arranged underground. Japanese designers [83] tried to transform underground parking into shopping units. The transformation of underground spaces is challenging owing to the higher requirements of evacuation, fire prevention, etc. In addition, underground spaces usually function as urban shelters. Therefore, there are relatively few cases of such retrofits to date. However, for their significant share of high-density urban parking spaces, their economic potential for retrofitting is gradually gaining attention. In the future, these spaces could be used for urban agriculture, storage, or data centers [77]. 

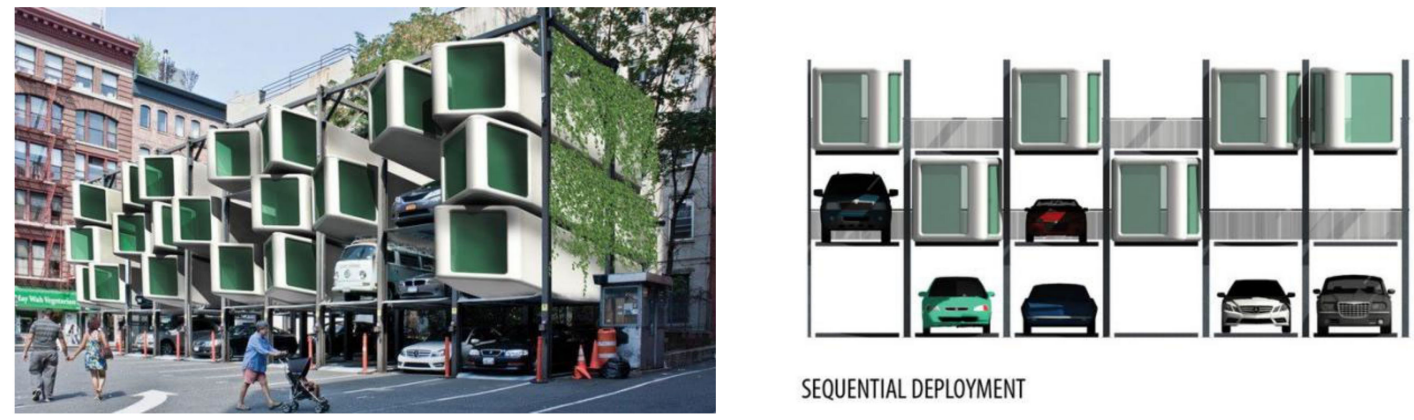

SEQUENTIAL DEPLOYMENT

Figure 5. Parking lot conversion project practice: UpLIFT, adapted from [82]. Copyright $2021 \mathrm{atr}+\mathrm{d}$.

The sustainable renewal and retrofitting of parking spaces is not an easy task. It involves economic, social, environmental, and other related factors [84]. Based on experience from existing cases $[45,85,86]$, the major constraints of garage renewal and retrofitting are low floor heights, sloped ramps, limited structural load-carrying capacity, and excessive flat areas, as well as the inadequate sizes and numbers of stairs, elevators, and entrance/exit. Other factors include the absence or shortage of various plumbing facilities (e.g., heating ventilation, air conditioning and fire protection systems), the lack of exterior envelope enclosures, rough architectural treatment, unsuitable fire compartment design, etc. All these factors need to be taken into consideration in the renewal process and stay consistent with the design specifications of the target function (Figure 6).
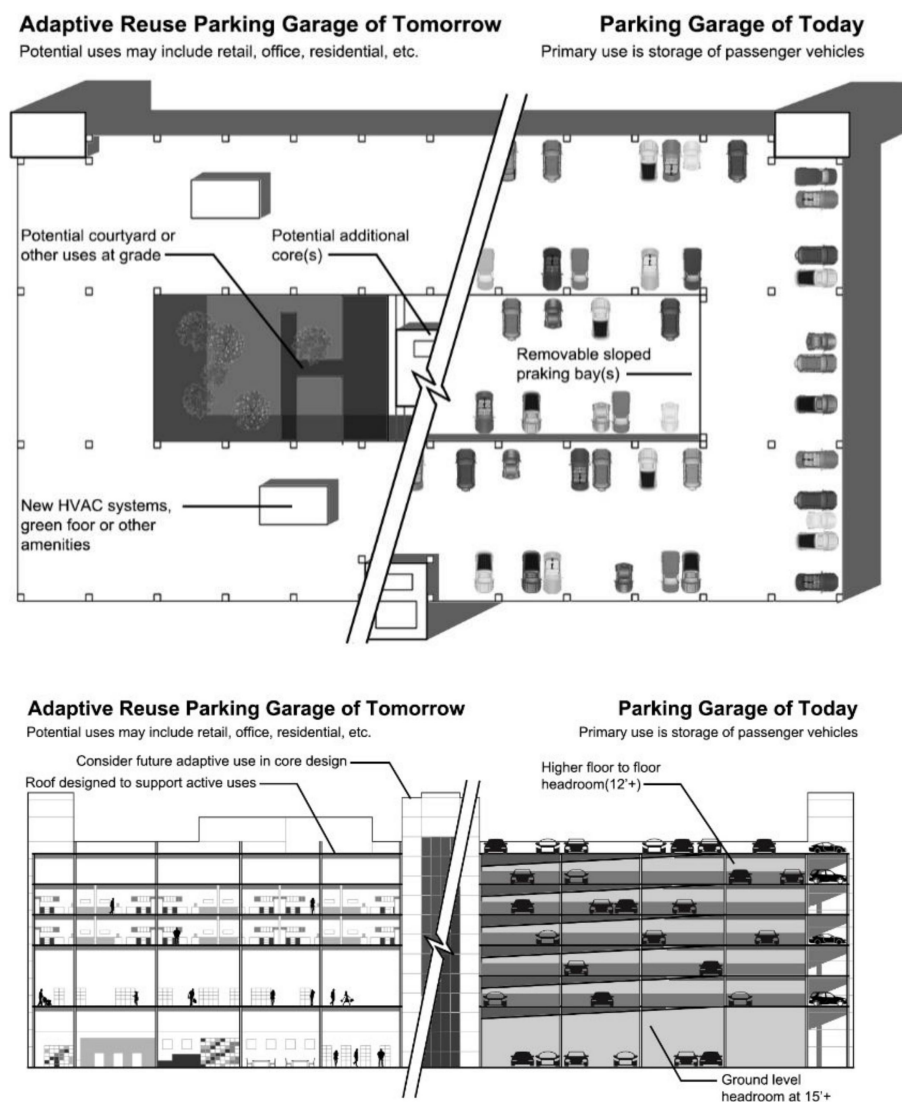

Figure 6. The countermeasures against major constraints of garage retrofitting, adapted from [45]. Copyright 2021 Taylor and Francis Group LLC-Books (for first figure). 


\subsection{Overview of the Research Status}

Overall, there is a trend in frontier exploration for parking space renewal worldwide, and most of the literature and practice is concerned with this scenario. However, in response to the challenge of the sustainable reuse of several parking spaces under the SAV scenario, the academic community, especially the architectural planning theory community, has not yet formed corresponding design theories and methods. The main shortcomings of the current research on parking space retrofitting under SAV scenarios are presented as follows:

1. A systematic perspective on the renewal of urban space is absent. Parking spaces belong to the static transportation system of the city, and their renewal and retrofitting require a comprehensive consideration of the entire system. If macroscopic planning assessments and microscopic architectural plans are not bridged to form common design guidelines for achieving rigid control and flexible guidance, it will be challenging to adapt to the diachronic and dynamic retrofit process of the parking space system, as well as to achieve the goal of sustainable development;

2. The scientific planning of retrofitting design projects is neglected. Although the current theoretical research focuses mainly on the demand forecast of parking spaces and the exploration of SAV parking facility designs, it does not consider other important aspects, such as comprehensive retrofit timing and function setting for scientific retrofit strategies and methods. Most of the existing retrofit projects are led by developers, and the lack of urban public interest factors affects the sustainability of urban renewal. Moreover, there are relatively few types of target functions for retrofitting, as well as a lack of functional restructuring for future cities;

3. Practical guidelines for the design process are absent. Although the retrofitting of different types of parking spaces faces common challenges, their spatial compositions vary significantly. The existing research does not address how to adopt the retrofitting experience of existing projects to form practical guidelines for promoting design and management continuously in the complex design process, as well as for facilitating the generation of novel theoretical paradigms and implementation systems for renewal.

Therefore, to address the potential demand for the renewal and retrofit of a large number of urban parking spaces in the future, and to realize a new type of urbanization in the context of digitalization in the future, there is an urgent need to establish a systematic theoretical approach and develop practical response techniques from the perspective of sustainable development.

\section{A Proposal on the Method for Sustainable Renewal of Parking Space under SAV Scenarios}

\subsection{Four Key Issues}

The sustainable retrofit and reuse of urban parking spaces is a systematic, diachronic, and complex process. Parking spaces are fragmented in cities, are widely distributed, and are huge in scale. Moreover, different parking spaces have different features, such as roadside parking, on-street parking, garage building, underground garage, under-viaduct parking space, building rooftop parking, etc., with large morphological differences. For sustainable renewal and retrofitting, targeted policies should be implemented according to the different features of parking spaces. These policies include the timing, content, and mode of retrofit, as well as specific design strategies. Therefore, this research intends to focus on four key issues or problems involved in the sustainable renewal and retrofitting of urban parking spaces under the SAV scenario: how many to renew (i.e., demand forecast analysis), when to renew (i.e., renewal timing evaluation), what to update to (i.e., function replacement decision), and how to renew (i.e., design empirical study). Through this, the study aims to establish a new paradigm. It hopes to form a guidance and control framework unifying the macro-, meso- and micro-levels, and propose a technical method adaptable to different renewal times, categories, and cases. This will help facilitate the dynamic process of the sustainable renewal of systemic spaces (Figure 7). 


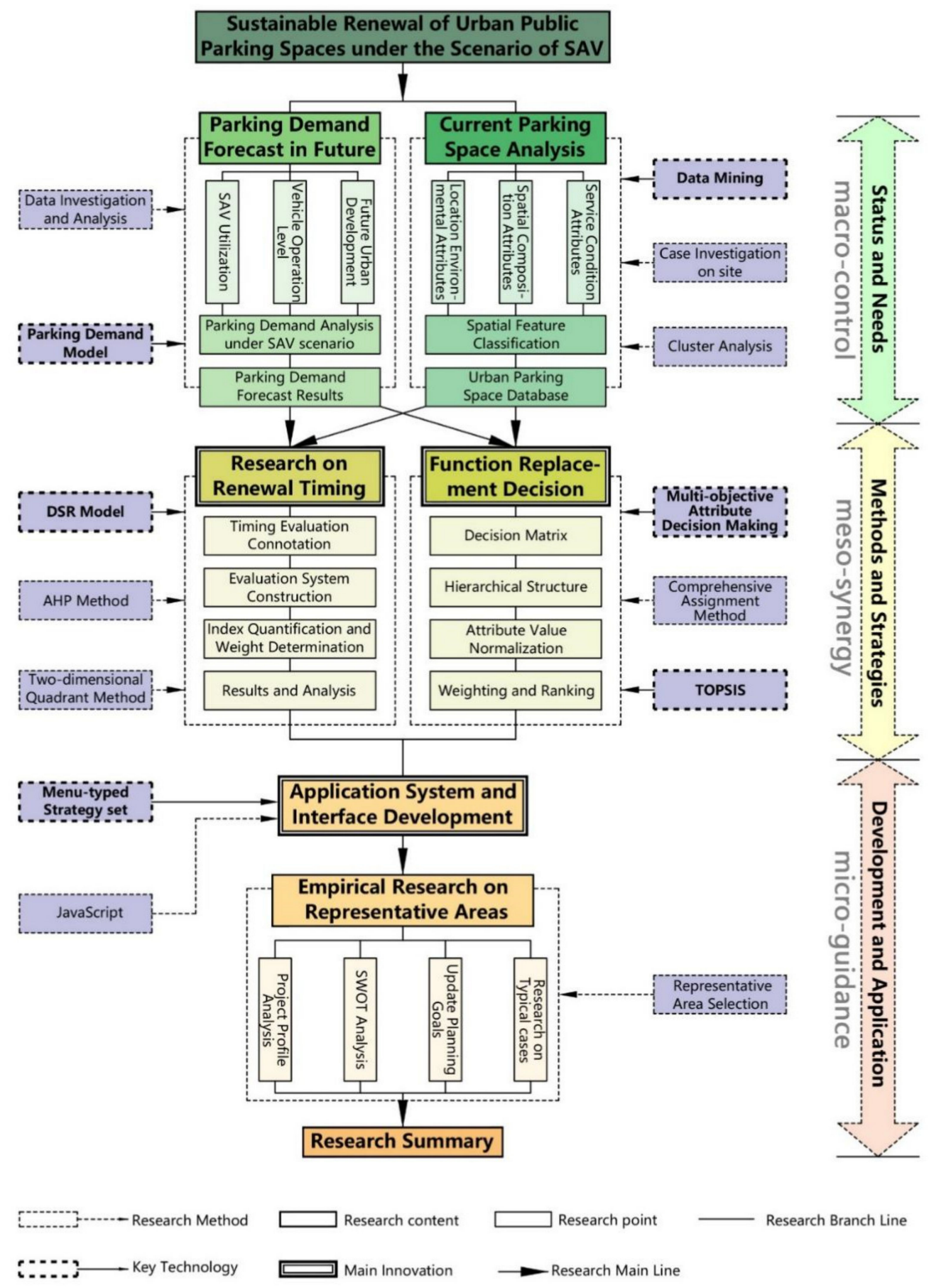

Figure 7. Four key issues involved in the parking space renewal process.

3.2. Status Quo Analysis of Urban Parking Spaces and Demand Forecasting under SAV Scenario

Currently, situation analysis and demand forecasting are carried out at the macro-city scale. The data collection includes data mining and on-site surveys. The data categories are the features and characteristics of existing parking spaces, including location environment, spatial composition, and usage. Parking space information of the designated areas in the cities under study is obtained from open source databases such as online maps, mobile parking apps, and city brain data platforms [87], collating photos, geographic coordinates, parking fees, numbers of spaces, numbers and locations of entrances and exits, and other geographic and economic information. At present, data mining technology based on Python has been widely used. There are also several online data collectors, which make data crawling relatively easy. In cases of missing network data for specific building 
structures, equipment, and decor, it is necessary to identify representative areas in cities as per the research scope and conduct field investigations. With data from the above sources, important spatial features can be filtered and organized, based on which data structures and databases can be established. Further, clustering analysis is adopted to subdivide existing surfaces, underground parking (garage), and on-street parking spaces into different sub-types. By comparing the distribution of parking space types in different cities and different areas of the city, an initial analysis of the project's renovation can be formulated.

Forecasting the demand for parking spaces is a prerequisite for urban parking space planning. At present, parking demand prediction models are mainly divided into three types [88]: (i) models based on the relationship between land use and parking facilities, (ii) travel attraction models based on the relationship between parking demand and travel, and (iii) models based on correlation analysis and regression analysis. In this study, the demand forecasting under the SAV scenario is founded on the modification of the existing model based on the analysis of land use and traffic impact [89]. This model makes predictions based on land use type and location traffic conditions. Compared with previous research methods [90-92], its advantages are the easy accessibility of data with relatively accurate results. The method of model modification is to adjust the parking demand coefficients of plots of different land use properties through a survey of the acceptance and use characteristics of SAV. The survey includes the reports of authoritative organizations (e.g., [93-96]) and the investigations of local people of different ages and vocations. This makes the model modification more regionally targeted. Accordingly, the number and area of urban parking spaces available for renewal can be determined at different time points in the future.

\subsection{Time-Series Evaluation of Urban Parking Space Renewal under SAV Scenarios}

The coordinated development of urban parking space renewal is a complex, dynamic, and long-term process. From a practical perspective, the driving-state-response (DSR) model is suitable for the establishment of an index system, a model, and a method for the time-series evaluation of the sustainable renewal of urban parking spaces. The DSR model is commonly adopted in the establishment of the index system of environmental evaluation. It is a construction method for index systems developed to measure the regional environment and sustainable development [97-99]. The DSR model has a relatively close relationship with the environmental objectives of sustainable development, and reflects a robust management idea. Based on the research purpose and object, the elemental composition of the existing DSR model should be improved according to the special characteristics of urban parking spaces. The driving force indicators primarily express the driving role of the regional and local environment, consisting of the distribution of business types, traffic conditions, and public service facility configuration. Status indicators mainly express the redevelopment potential of a parking space itself, composed of ecological status, building status, and other site status. The response indicators are mainly considered as the potential support for property owners and sector managers.

The evaluation index quantification process adopts the assignment method, which classifies each index evaluation level (from high to low) into four categories: highly suitable, moderately suitable, barely suitable, and unsuitable. For each index, it also assigns different scores and employs analytic hierarchy process (AHP) analysis to determine the weight. The renewal timing is determined using the four-quadrant method (Figure 8), which combines the results of the evaluation of the driving force and status aspects of the DSR model. It can divide the existing urban parking space renewal potential (from near-term to long-term) into strong driving force and good status, strong driving force and bad status, weak driving force and good status, as well as weak driving force and bad status. According to the three stages of near-term, mid-term, and long-term developments, the renewal time sequence of each parking space is determined, which can provide a basis for the decision-making of planners and administrative authorities. 


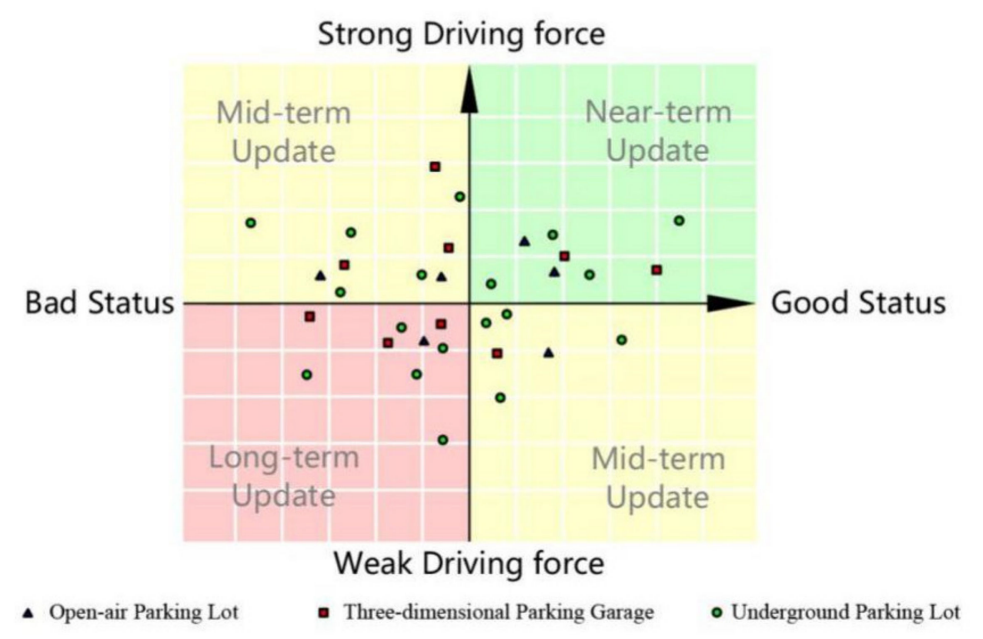

Figure 8. A schematic diagram of results derived by the driving-state-response (DSR) model.

Differing from the macro perspective of demand forecasting, the update sequence evaluation can be carried out in a smaller area or spatial unit. Based on basic parcel conditions such as the parking status, demand, land use mode, and area, spatial clustering [100] can merge land parcels with a relatively close reconstruction mode and spatial location into a basic unit. Due to the diverse quantity and distribution of parking spaces in different areas of the city, determining the development timing based on the renewal demand of different areas can ensure the effectiveness of the renewal implementation.

3.4. Decision-Making Approach to the Functional Replacement of Urban Parking Spaces under SAV Scenarios

The functional replacement selection of parking space is a typical multi-objective challenge, which is characterized by the incommensurability among the objectives and the contradiction between each attribute index. Based on the multi-objective and multiattribute characteristics of parking space functional replacement, this study combines the multi-objective attribute decision model with functional replacement evaluation to explore the objective determination method for the sustainable renewal of parking spaces. The library for function alternatives includes traditional functions such as retail, restaurants, offices, culture and recreation facilities, and warehouses, as well as new functions for future cities, such as urban agriculture [101,102], data centers [103], maker spaces [104], SAV parking [66], etc. According to the general process of multi-objective attribute decisionmaking [105], the parking space function replacement decision analysis goes through six steps: decision matrix building, recursive structure construction, attribute value normalization processing, indicator weight determination, comprehensive attribute utility value calculation, and alternative ranking.

The decision matrix is a mathematical representation of the values obtained from the corresponding attributes of each alternative, which can illustrate the decision information of the alternatives in each indicator attribute. Regarding the requirement for different stakeholders involved in parking space renewal (builders, operators, government departments, users, etc.), two criteria for the functional replacement challenge are proposed: economic and environmental. Furthermore, this study also proposes the two major categories of their corresponding indicators, cost and benefit, and specifically divides them into five attributes: construction cost, operation cost, land cost, overall environment, and internal environmental impact. Owing to the differences in indicators of economic and environmental costs, a combined assignment method is adopted to assign the weight of each indicator, which considers the importance of both quantitative and qualitative indicators (Figure 9), and avoids the limitations of the subjective assignment method. 


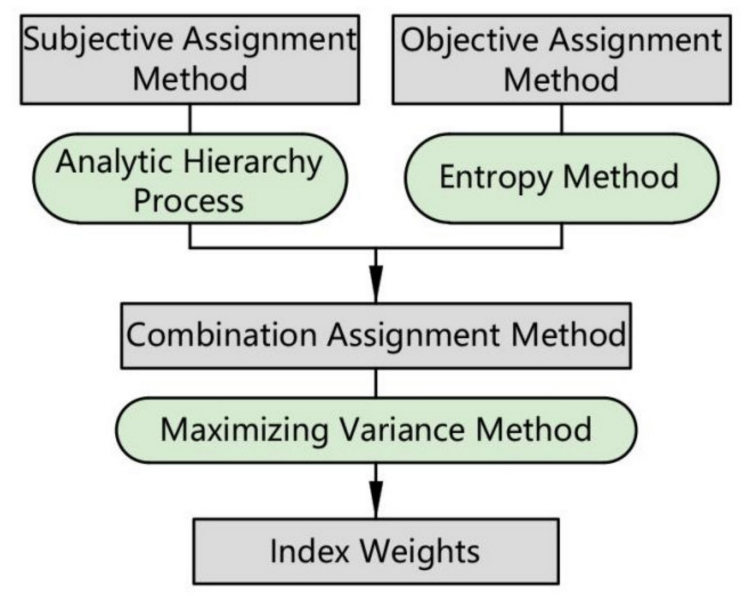

Figure 9. Combination weight assignment method.

The TOPSIS (Technique for Order Preference by Similarity to an Ideal Soluation) method can be used to rank the alternatives in the functional replacement decision-making process, and identify the best renewal option for different types of parking spaces. Based on the raw data matrix after normalization, the TOPSIS method finds the positive and negative ideal solutions in a finite number of solutions [106,107]. This method also obtains the relative distances from an alternative to the positive ideal solution and the negative ideal solution, and thus derives the relative proximity to the positive ideal solution for an alternative. The alternatives of functional replacement are ranked according to relative proximity, in order to evaluate the merits of each alternative.

\subsection{Empirical Studies and Strategies Optimization}

A design empirical study is conducted to validate the time-series evaluation method and function replacement decision-making approach of sustainable urban parking space renewal. Certain representative areas or spatial units are selected for the cross-analysis of SWOT (Strengths, Weaknesses, Opportunities and Threats) elements concerning parking space renewal. The overall objectives and strategies for regional renewal are proposed. Afterwards, the renewal time and function setting of each parking space in the area are determined. Eventually, thematic urban design guidelines are formed for these selected spatial units.

On this basis, detailed case studies and architectural designs of the sustainable renewal of typical cases are to be completed, including functional zoning, entrances and exits, traffic system, fire safety and evacuation, important node spaces, detailed structure, general plan environment, etc. Based on the parking space prototypes refined with general commonality, the research studies and summarizes appropriate strategies for their spatial renewal. In addition, topology is adopted as the evolutionary medium to design a "menu" of various morphological design strategies and spatial organization patterns via the analysis of variable factors, which can provide a basis for professionals (Figure 10). The visualization of this "menu" helps the designers to communicate with the developer and ultimately to make the best choice for the actual design solution according to the diverse realities of the construction site. 


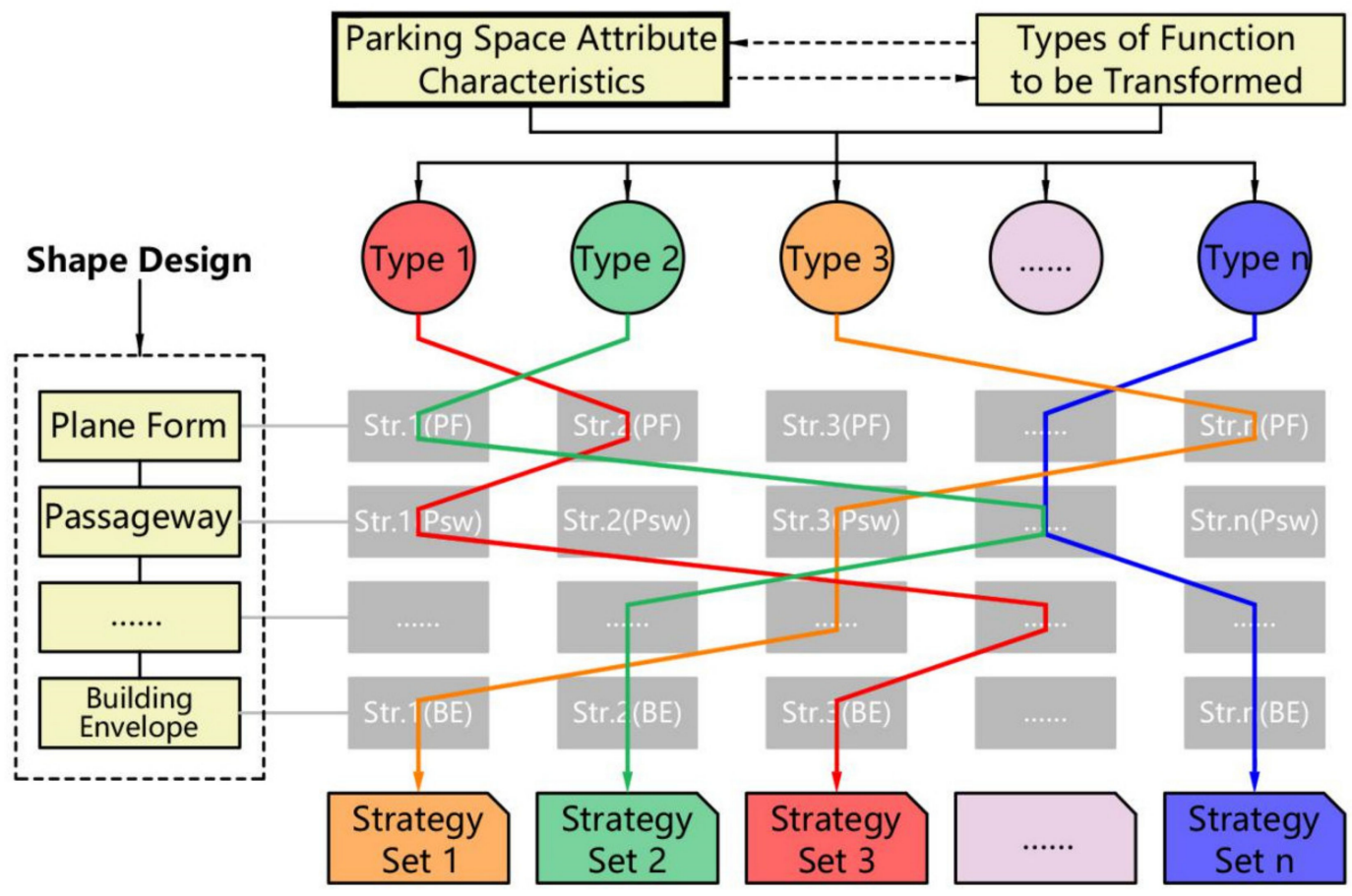

Figure 10. Renewal strategy menu generation diagram.

Combining four aspects, including demand forecasting, time-series evaluation, functional replacement, and design strategy, the application system and its interface are developed for the implementation of the renewal project. Its advantage is that it can be used as a working platform for project participants to integrate and share information. The proposed system adopts a hierarchical and modular design. It is divided into four basic modules. The architecture of the application system is shown in Figure 11. The first is the indicator system module, which is responsible for the online creation of new evaluation indicator systems, including the input of indicators, the construction of indicator scoring criteria, and the online calculation of indicator weights. The second is the indicator system management module, which is responsible for managing and viewing the evaluation model. The third is the calculation module, which is responsible for collecting the information of evaluation objects according to indicators and performing comprehensive indicator calculations. The fourth is the result display module, which is responsible for displaying and comparing results for which evaluation and calculation have been completed. 


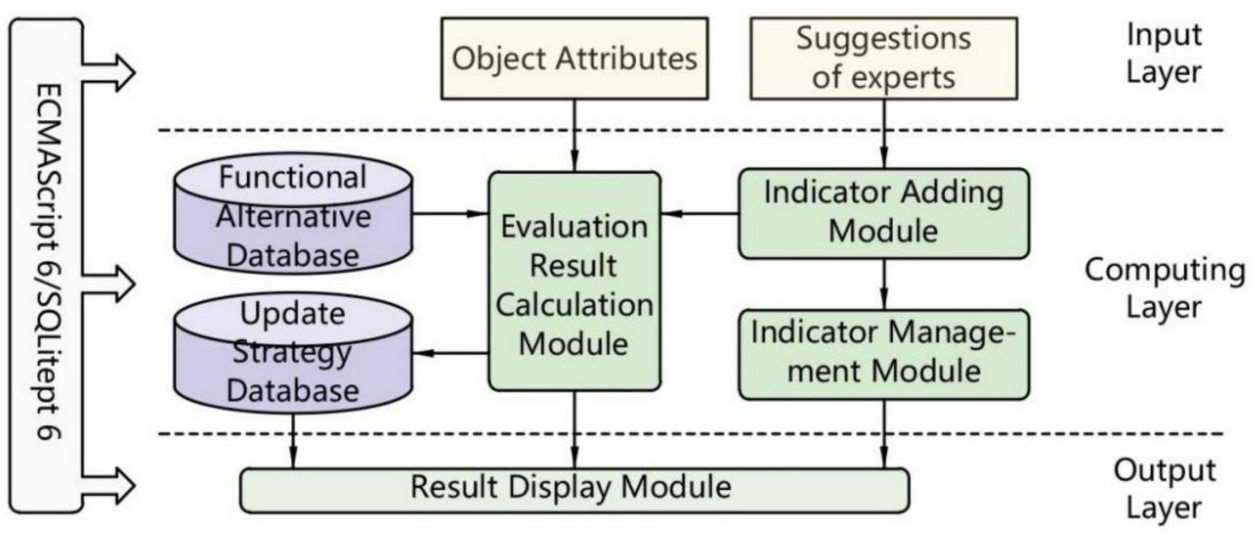

Figure 11. Application system architecture diagram.

\section{Discussion}

\subsection{Examples of Applications}

The renewal methods and framework for the urban space systems established in this study have several applications based on planning stage and project type. For example, planners and urban administrative departments regularly prepare relevant guidelines for urban master planning, construction detailed planning, special planning, and urban design. For architects engaged in the retrofitting design of specific cases, the study framework can be used to compare and modify the proposed scheme. Meanwhile, with an increase in the number of completed cases in the case library, the recommendations become more accurate, which will help architects' design decisions. For the owners of the parking space, it could help them better understand the value of their properties, and enhance social sustainability during self-organized renewal.

The established guidance and control framework unifies the macro-, meso- and microlevels, and proposes an urban renewal model that differentiates cases based on time and category. If the indicators and weights are adjusted appropriately, it can be applied to similar urban systemic spaces; for example, the evaluation of the utilization of renewable energy on urban building roofs [108], the redevelopment and reuse of low-utilized urban spaces (such as under- and over-head spaces, small green spaces, etc.) [109], the coordination of architectural styles in the whole city [110], and urban color planning [111], among other thing. These related urban issues are pertinent to the sustainable goals of urban ecology, environmental health, urban resilience, disaster prevention, and heritage protection.

\subsection{Contributions to Management Theory and Practice}

The significance of this research also lies in its potential to transform our value concept, design approach, talent development, implementation strategy, and management system for the transformation of stock spaces.

1. The current research and practice of smart cities primarily focus on the integrated use of several novel technologies [112]. However, the most essential driving force for urban spatial reconfiguration is the new lifestyles of people. To achieve sustainable development, the spatial patterns of future cities should be adapted to these lifestyles. As Michel [113] mentions in his book, urban planners and designers should accurately predict the picture of future life in order to grasp the fundamental principles of spatial renewal design;

2. Parking space renewal requires a systemic and dynamic perspective. Urban parking spaces are a subsystem of the urban system, and are intertwined with other urban spaces and functional systems [26,38]. City-wide urban parking renewal is for the whole network, not only for any individual case alone at the micro level. The retrofitted spaces of the old system will be broken down and integrated into the novel urban spatial system. Simultaneously, the retrofitting of the parking space system is 
also diachronic and dynamic, and needs to be constantly corrected according to the changing objectives of urban development. Therefore, the renewal design approach necessarily combines both assessment at the macro level and design at the micro level;

3. The sustainable renewal of urban parking spaces is an adaptive retrofit [64,77]. Compared with other renewal modes, its design conditions are more complex and difficult, and it requires more assessments in the planning stage. In particular, for large-scale underground parking garages, their structures are usually more complex than aboveground garages and their design regulations are more restrictive. To cope with this, the comprehensive knowledge of professional designers and managers is needed. Therefore, the new profession of retrofit experts in urban space may come into being;

4. Urban parking space retrofitting is an approach to realizing smart urban growth [114]. Compared with brownfield site renewal projects, the implementation of parking space retrofitting requires more refined management, which involves a complex balance of public and private interests, the participation of multiple decision makers, and the adjustment of property rights. The success of San Francisco's on-street parking retrofit project [67] demonstrates that the implementation approach of the Private Public Projects (PPP) is also applicable to parking space retrofitting. This agrees well with the designation of responsible parties and the guarantee of subsequent operation management [115];

5. Novel renewal paradigms will also inevitably trigger a change in the urban management system. The renewal system should be able to combine top-down and bottom-up forces and integrate the management approaches of rigid control and flexible guidance $[116,117]$. The novel urban renewal process will allow the design and planning of individual buildings to be linked with existing statutory plans at different levels, thus realizing an orderly and coordinated process of the renewal of urban spatial systems. Accordingly, it is necessary to modify the existing policy structure system, integrate the management functions of different administrative departments, and establish a special management body for urban renewal [118].

\subsection{Research Limitations and Recommendations for Further Research}

There are some limitations to this research. First, although the relevant literature collection was relatively comprehensive, there is currently little research on this new topic. Second, a quantitative analysis of relevant literature and design cases is lacking. Due to the insufficiency of data in the qualitative analysis and inferences in this study, the classification and comparison of documents are based on subjective judgments. Third, the theoretical analysis and framework in this research are preliminary, and there are many details worthy of deliberation, and these should be continuously optimized during the implementation process. Fourth, the proposed method involves many interdisciplinary technologies, which could not be explained in detail here in the interest of keeping this paper concise. Considering the universality and implementation potential of the method, this research only chooses the commonly used technical means, which may have better alternatives.

Despite the above shortcomings, this research is innovative and valuable. It analyzes the problems, significance, and status quo of the renewal of urban parking spaces under the SAV scenario, as well as preliminary solutions. It proposes a new renewal model that lays a groundbreaking foundation for future research. Further research must investigate the following aspects. First, empirical research is needed in sample regions for verifying the effectiveness and application of the proposed method. This should focus on the modification and concretization of the preliminary framework according to different situations. Second, the application of clustering and similarity judgments [119] based on the properties of many renewal cases mined from the internet (such as shared design platforms, etc. [120,121]) can improve the accuracy of reference cases for the design process. Furthermore, intelligent algorithms (such as extension planning, etc. [122]) can help optimize the design strategies. Third, the evolved lifestyles and urban morphology promoted by SAV are profound and long-term. The issue of the renewal of parking spaces is only one piece of the puzzle in the 
urban design theory of the digital city. This should be integrated into the broader design theory for future digital living.

\section{Conclusions}

This paper analyzes the development status of the SAV technology, reviews the relevant theories and cases of parking space retrofit, and constructs a research framework for a sustainable renewal method for parking space systems under SAV scenarios. It concludes that:

1. In the SAV era, many parking spaces will be gradually renovated and transformed for other uses, and the renewal of parking spaces will become an important issue for sustainable urban development in the future;

2. Parking spaces have the characteristics of large total volume, wide distribution, and fragmentation, which respectively make the renewal process systematic, diachronic, and complicated;

3. The renewal of parking spaces is gaining scholarly attention, but the existing research and practice lack adaptable methods for the sustainable renewal of many parking spaces in SAV scenarios;

4. A theoretical framework that unifies macro-prediction, meso-collaboration, and microguidance is required to form guidance and control methods for the time sharing and classification of sub-items for the parking space renewal process;

5. The sustainable renewal of urban parking space under SAV scenarios provides a theoretical, practical, and institutional opportunity for innovative urban renewal in the digital era.

Author Contributions: Conceptualization, B.X.; Formal analysis, J.W. (Jindong Wu) and J.W. (Jiaqi Wang); Methodology, B.X.; Resources, B.X.; Writing—original draft, B.X.; Supervision, B.X.; Funding acquisition, B.X.; Visualization, J.W. (Jiaqi Wang), Y.F., H.S. and J.S.; Writing Original Draft, J.W. (Jiaqi Wang) and Y.F.; Writing - review \& editing, H.S., J.S. All authors have read and agreed to the published version of the manuscript.

Funding: This research was funded by Basic Public Welfare Research Program of Zhejiang Province (grant number: LGF21E080012) and The Opening Fund of State Key Laboratory of Green Building in Western China (grant number: LSKF202003).

Conflicts of Interest: The authors declare no conflict of interest.

\section{References}

1. The Economist. Autonomous Vehicles Are Just Around Corner; The Economist: London, UK, 2018.

2. The Economist. Autonomous Vehicles; The Economist: London, UK, 2018.

3. Alessandrini, A.; Campagna, A.; Delle Site, P.; Filippi, F.; Persia, L. Automated Vehicles and the Rethinking of Mobility and Cities. Transp. Res. Proc. 2015, 5, 145-160. [CrossRef]

4. Parkin, J.; Clark, B.; Clayton, W.; Ricci, M.; Parkhurst, G. Autonomous vehicle interactions in the urban street environment: A research agenda. Proc. Inst. Civ. Eng. Munic. 2018, 171, 5-25. [CrossRef]

5. Hardy, B.; Fenner, R.A. Towards the sustainability of road transport through the introduction of AV technology. In Proceedings of the Institution of Civil Engineers-Engineering Sustainability; Thomas Telford Ltd.: London, UK, 2015; Volume 168, pp. 192-203. [CrossRef]

6. Fagnant, D.J.; Kockelman, K. Preparing a nation for autonomous vehicles: Opportunities, barriers and policy recommendations. Transp. Res. Part A 2014, 77, 167-181. [CrossRef]

7. Fagnant, D.J.; Kockelman, K.; Bansal, P. Operations of a shared autonomous vehicle fleet 2 for the Austin, Texas, market. Transp. Res. Rec. 2019, 2563, 98-106. [CrossRef]

8. Sperling, D. Three Resolutions: Steering Automated, Shared and Electric Vehicles to a Better Future; Island Press: Washington, DC, USA, 2018.

9. The Boston Consulting Group (BCG). Self-Driving Vehicles, Robo-Taxis, and the Urban Mobility Revolution. Available online: https:/ /image-src.bcg.com/Images / BCG-Self-Driving-Vehicles-Robo-Taxis-and-the-Urban-Mobility-Revolution_tcm9-5 9714.pdf (accessed on 13 March 2021).

10. United Nation. Amendments to Article 8 and Article 39 of 1968 Convention on Road Traffic; United Nation: New York, NY, USA, 2016.

11. U.S. Department of Transportation. Federal Automated Vehicles Policy; U.S. Department of Transportation: Washington, DC, USA, 2016. 
12. National Development and Reform Commission. Innovative Development Strategy of Intelligent Vehicles; National Development and Reform Commission: Beijing, China, 2020.

13. Ministry of Industry and Information Technology of the People's Republic of China, The ministry of Public Security of the People's Republic of China, Ministry of Transport of the People's Republic of China. The Management Standard for Intelligent Network Connected Vehicle Road Test. Available online: http://xxgk.mot.gov.cn/2020/jigou/kjs/202006/t20200623_3317132.html (accessed on 13 March 2021).

14. Zhejiang Provincial Development and Reform Commission. Innovative Development Plan of Intelligent Vehicles in Zhejiang Province: From 2020 to 2025; Zhejiang Provincial Development and Reform Commission: Hangzhou, China, 2019.

15. Krueger, R.; Rashidi, T.H.; Rose, J.M. Preference for shared autonomous vehicles. Transp. Res. Part C 2016, 69, 343-355. [CrossRef]

16. Cosh, K.; Wordingham, S.; Ramingwong, S. Investigating public opinion regarding autonomous vehicles: A perspective from Chiang Mai, Thailand. In IT Convergence and Security 2017; Kim, K.J., Kim, H., Baek, N., Eds.; Springer: Singapore, 2017.

17. Lu, Z.; Du, R.; Dunham-Jones, E.; Park, H.; Crittenden, J. Data-enabled public preferences inform integration of autonomous vehicles with transit-oriented development in Atlanta. Cities 2017, 63, 118-127. [CrossRef]

18. AMiner. Artificial Intelligence and Autonomous Vehicle Research Report; AMiner: Beijing, China, 2018.

19. Zhang, W. Impact of intelligent transportation on urban space. Planner 2017, 2017, 78-82. (In Chinese)

20. Bagloee, A.S.; Tavana, M.; Asadi, M.; Olivier, T. Autonomous vehicles: Challenges, opportunities, and future implications for transportation policies. J. Mod. Transp. 2016, 8, 284-303. [CrossRef]

21. IEEE. News Release. Available online: https://www.ieee.org/about/news/2012/5september-2-2012.html (accessed on 13 March 2013).

22. National Parking Association. Smart Solutions for Parking in an Autonomous Future; National Parking Association: Washington, DC, USA, 2019.

23. Lövgren, J. The Impact of Autonomous Mobility in Urban Planning—Relating to the Future of Urban Mobility. Master's Thesis, Chalmers University of Technology, Gothenburg, Sweden, 2017.

24. Duarte, F.; Ratti, C. The impact of autonomous vehicles on cities: A review. J. Urban Technol. 2018, 25, 3-18. [CrossRef]

25. Gruel, W.; Stanford, J.M. Assessing the long-term effects of autonomous vehicles: A speculative approach. Transp. Res. Proc. 2016, 13, 19-29. [CrossRef]

26. Shoup, D. Parking and the City; Routledge: New York, NY, USA, 2018.

27. Mitchell, W.; Borroni-Bird, C.; Burns, L. Reinventing the Automobile: Personal Urban Mobility for the 21st Century; MIT Press: Cambridge, MA, USA, 2010.

28. Mitchell, A. Are We Ready for Self-Driving Cars? Available online: https://www.weforum.org/agenda/2015/11/are-we-readyfor-self-driving-cars / (accessed on 13 March 2021).

29. Schoettle, B.; Sivak, M. Potential Impact of Self-Driving Vehicles on Household Vehicle Demand and Usage; The University of Michigan Transportation Research Institute: Ann Arbor, MI, USA, 2015.

30. Wen, X. Investigation: How Will Autonomous Vehicles Reshape Urban Construction. Available online: http:/ / www.leiphone. com/news/201602/2AjTBodXgOi2wpQE.html (accessed on 13 March 2013).

31. CIC Consulting Industry Research Center. Analysis on the Demand of China's Intelligent Driving Market in the Next Five Years. Available online: http:/ / www.doc88.com/p-9176471635156.html (accessed on 13 March 2013).

32. Curtis, T.; Karlin-Resnick, J. Autonomous Vehicles and the Future of Parking. Available online: http://nelsonnygaard.com/ wp-content/uploads/2017/04/Our_Views_on_Autonomous_Vehicles_and_The_Future_of_Parking.pdf (accessed on 13 March 2013).

33. Xie, S.; Yi, W.; Lei, X. Investigation on street space optimization design under the influence of automatic driving. In Proceedings of the China Society of Urban Planning in 2018 of the Conference of China Association of City Planning, Hangzhou, China, 24 November 2018; China Architecture Publishing \& Media Co., Ltd.: Beijing, China, 2018; Volume 5, pp. $1152-1159$.

34. Chapin, T.; Stevens, L.; Crute, J.; Jordan, C.; Rokyta, A.; Washington, A. Envisioning Florida's Future: Transportation and Land Use in an Automated Vehicle World. Florida Department of Transport: Tallahassee, FL, USA, 2016.

35. Zhang, W.; Guhathakurta, S.; Fang, J.; Zhang, G. Exploring the impact of shared autonomous vehicles on urban parking demand: An agent-based simulation approach. Sustain. Cities Soc. 2015, 19, 34-35. [CrossRef]

36. Shoup, D. The High Cost of Free Parking; Routledge: New York, NY, USA, 2009.

37. Liu, Q.; Wang, J.; Li, Y. Sustainable urban parking management: International Comparison and reference. Int. Urban Plan. 2019, 34, 63-69. [CrossRef]

38. Urban Land Institute, National Parking Association. The Dimensions of Parking; Urban Land Institute: Washington, DC, USA, 2010.

39. Michael, M. Parking Requirements and Housing Development. J. Am. Plan. Assoc. 2013, 79, 49-66.

40. United States Environmental Protection Agency. Parking Spaces and Community Places: Finding the Balance through Smart Growth Solutions; United States Environmental Protection Agency: Washington, DC, USA, 2006.

41. Chester, M.; Horvath, A.; Madanat, S. Paking infrastructure: Energy, emissions, and automobile life-cycle environmental accounting. Environ. Res. Lett. 2010, 5, 034001. [CrossRef]

42. Davis, A.Y.; Pijanowski, B.C.; Robinson, K.D.; Kidwell, P.B. Estimating parking lot footprints in the Upper Great Lakes Region of the USA. Landsc. Urban. Plan. 2010, 96, 69-77. [CrossRef] 
43. National Bureau of Statistics (China). Statistical Communique on the 2019 National Economic and Social Development; National Bureau of Statistics (China): Beijing, China, 2020.

44. Ministry of Housing and Urban-Rural Development of the People's Republic of Chia (MOHURD). Code for Urban Parking Planning GB/T51149-2016; MOHURD: Beijng, China, 2016.

45. International Parking Institute. A Guide to Parking; Routledge: New York, NY, USA, 2018.

46. Henley, S. The Architecture of Parking; Thames \& Hudson: New York, NY, USA, 2009.

47. Ben-Joseph, E. Rethinking a Lot: The Design and Culture of Parking; The MIT Press: Cambridge, MA, USA, 2015.

48. Lipson, H.; Kurman, M. Driverless: Intelligent Cars and the Road Ahead; The MIT Press: Cambridge, MA, USA, 2016.

49. Martinez, L.M.; Viegas, J.M. Assessing the impacts of deploying a shared self-driving urban mobility system: An agent-based model applied to the city of Losbon, Portugal. Int. J. Transp. Sci. Technol. 2017, 6, 13-27. [CrossRef]

50. Brenden, A.P.; Kristoffersson, I.; Mattsson, L. Future Scenarios for Self-Driving Vehicles in Sweden; KTH Royal Institute of Technology: Stockholm, Swenden, 2017.

51. Simith, C. Turning Transportation Challenges and Opportunities Presented to the City of Vancouver by Autonomous Vehicles; The University of British Columbia: Vancouver, BC, Canada, 2016.

52. Zhang, X. New technology and future urban transport countermeasures. Urban Archit. 2018, 10, 18-22.

53. McDonald, S.S.; Rodier, C. Envisioning automated vehicles within the built environment: 2020, 2035, and 2050. In Road Vehicle Automation; Meyer, G., Beiker, S., Eds.; Springer International Publishing: New York, NY, USA, 2015.

54. National Association of City Transportation Officials. Blueprint for Autonomous Urbanism, 2nd ed.; National Association of City Transportation Officials: New York, NY, USA, 2019.

55. Wang, W.; Zhu, J.; Zheng, X. Investigation on urban spatial characteristics in the era of autonomous vehicles. Planner 2018, 12, 155-160. (In Chinese)

56. Zhang, J.; Yu, T. Research on urban space governance under the influence of shared vehicles: A case study of Nanjing. Urban Res. 2018, 10, 21-27. (In Chinese)

57. Perkins \& Will. Design for Future Mobility: Developing a Framework for the Livable Future City; Perkins \& Will: Washington, DC, USA, 2019.

58. Zhang, W.; Guhathakurta, S. Parking spaces in the age of shared autonomous vehicles: How much parking will we need and where? Transp. Res. Rec. 2017, 1, 80-91. [CrossRef]

59. Zhang, W.; Wang, K. Parking futures: Shared automated vehicles and parking demand reduction trajectories in Atlanta. Land Use Policy 2021, 91, 103963. [CrossRef]

60. Bischoff, J.; Maciejewski, M.; Schlenther, T.; Nagel, K. Autonomous vehicles and their impact on parking search. IEEE Intell. Transp. Syst. Mag. 2018, 11, 19-27. [CrossRef]

61. Simons, R.; Feltman, D.; Malkin, A. When would driverless vehicles make downtown parking unsustainable, and where would the driverless car fleet rest during the day? J. Sustain. Real Estate 2018, 10, 3-32. [CrossRef]

62. Ziegenfuss, K. Constructing Use in Surface Parking Lots: Strategies for Enhancing Lots as Part-Time Public Spaces. Master's Thesis, Massachusetts Institute of Technology, Cambridge, MA, USA, 2009.

63. Xu, X.; Xu, N.; Wang, W. Urban space transformation and urban design strategy under the background of automatic driving. Urban Dev. Res. 2020, 1, 44-50. (In Chinese)

64. Simons, R.A.; Kline, J. Urban adaptive reuse potential from the architect's perspective. In Driverless Cars, Urban Parking and Land Use; Simons, R.A., Ed.; Routledge: New York, NY, USA, 2020.

65. Ferreira, M.; Damas, L.; d'Orey, P.M.; Conceicao, H.; Fernandes, R.; Steenkiste, P.; Gomes, P. Self-automated parking lots for autonomous vehicles based on vehicular ad hoc networking. In Proceedings of the 2014 IEEE Intelligent Vehicles Symposium Proceedings, Dearborn, MI, USA, 8-11 June 2014; pp. 472-479.

66. Nourinejad, M.; Bahrami, S.; Roorda, M.J. Designing Parking Facilities for Autonomous Vehicles. Transp. Res. Part B 2018, 109, 110-127. [CrossRef]

67. City of San Francisco. 51 "Parklets". Available online: https://www.lgc.org/wordpress/docs/events/first_thursday_dinners/ ftd_2013_Parklet_Manual-may.pdf (accessed on 13 March 2013).

68. Lauren, J. Kimbal Musk Launches a Revolutionary Shipping Container Farm Initiative in Brooklyn. Available online: https: / /inhabitat.com/kimbal-musk-just-launched-a-revolutionary-shipping-container-farm-initiative-in-brooklyn/ (accessed on 13 March 2013).

69. National Association of City Transportation Officials. Urban Street Design Guide; Island Press: Covelo, CA, USA, 2013.

70. Taylor, A. The Boxing Ring parklet, on Pike Street, outside Franks Old Town Cafe and Cutman Barbershop. Available online: https: //cdn2.cincinnatimagazine.com/wp-content/uploads/sites/5/2016/06/CM_JULY16_FL_Park_Boxing-e1466611992674.jpg (accessed on 22 March 2021).

71. Northwestern University. About the Garage. Available online: https://thegarage.northwestern.edu/about/the-garage/ (accessed on 13 March 2013).

72. Zeng, Q. TJAD new office building: Bus FAW. World Archit. 2016, 5, 104-105. (In Chinese)

73. Governing, D.K. Neglected Parking Garages Are Being Given New Purpose. Available online: https://www.govtech.com/fs/ Neglected-Parking-Garages-Are-Being-Given-New-Purpose.html (accessed on 13 March 2013). 
74. Logan, K. Continuing Education: Innovations in Parking Garages. Available online: https:/ /www.architecturalrecord.com/ articles/13928-continuing-education-innovations-in-parking-garages (accessed on 13 March 2013).

75. INHABITAT. Grass Coated Green-Roofed Parking Garage Concept for Tokyo. Available online: https://inhabitat.com/grasscoated-green-roofed-parking-garage-concept-for-tokyo/ (accessed on 13 March 2013).

76. Cilento, K. Parking Garage Adaptive Re-Use/KSS Architects. Available online: https://www.archdaily.com/65738/parkinggarage-adaptive-re-use-kss-architects (accessed on 13 March 2013).

77. Walker, A. Parking Garages Are Getting a Second Life as Places for People. Available online: https://www.curbed.com/2017/4 /26/15421594/parking-garages-driverless-cars-gensler (accessed on 13 March 2013).

78. Peters, A. These Future-Proof Parking Garages Can Easily Morph into Offices or Housing. Available online: https://www. fastcompany.com/90291136/these-futureproof-parking-garages-can-be-easily-turned-into-offices-or-housing (accessed on 13 March 2013).

79. Simons, R.A.; Ortlieb, M.; Owens, J. The Wedge-A Parking Expansion and Adaptive Reuse Case Study in Grand Rapids, Michigan. In Driverless Car, Urban Parking and Land Use; Simons, R.A., Ed.; Routledge: New York, NY, USA, 2020; pp. 350-367.

80. Calgray Municipal Land Corporation. Q\&A with the Design Team of 9th Avenue Parkade and Platform Innovation Centre. Available online: https:/ / www.calgarymlc.ca/newsletter/2020/2/24/ qampa-with-the-design-team-of-9th-avenue-parkadeand-platform-innovation-centre (accessed on 13 March 2013).

81. Urbanist. Modular Remix: Parking Garage Picked Apart, Reassembled Like LEGO. Available online: https://weburbanist.com/ 2017/05/30/modular-remix-parking-garage-picked-apart-reassembled-like-lego/ (accessed on 13 March 2013).

82. INHABITAT. UpLIFT Transforms Elevated Parking Spaces into a Hive of Prefabricated Tiny Homes! Available online: https: / /inhabitat. com/uplift-transforms-elevated-parking-spaces-into-a-hive-of-prefabricated-tiny-homes/ (accessed on 13 March 2013).

83. Corcoran, H. A Surprise Hides in This Tokyo Parking Garage. Available online: https://www.dwell.com/article/a-surprisehides-in-this-tokyo-parking-garage-655411cd (accessed on 13 March 2013).

84. Albersman, D.; Leedom, C.; Pandya, S. Adaptive reuse of parking structures. In A Guide to Parking International; Parking Institute; Routledge: New York, NY, USA, 2018; pp. 152-156.

85. McLnerney, J. Adaptive Reuse without Breaking the Bank: What Is Reasonable When Planning New Parking? Available online: https:/ / www.watrydesign.com/insights/adaptive-re-use-without-breaking-the-bank-what-is-reasonable-when-planningnew-parking (accessed on 13 March 2013).

86. Nettler, J. Replacing Parking with People: The Next Wave of Adaptive Reuse. Available online: https:/ / www.planetizen.com/ node/ 66057 (accessed on 13 March 2013).

87. Xu, Z.; Liu, Y. Research on the Development of Smart City Based on the Thought of "Urban Brain”. Reg. Econ. Rev. 2017, 2017, 102-106. (In Chinese)

88. Li, P.; Mu, K. Review and prospect of parking demand study. J. Taiyuan Univ. Technol. 2018, 36, 63-70. (In Chinese)

89. Wang, W.; Chen, X. Transportation Planning; China Communications Press Co., Ltd.: Beijing, China, 2019. (In Chinese)

90. Onyeka Bonaventure, O. The impacts of shared autonomous vehicles on car parking space. Case Stud. Transp. Policy 2020, 8 , 1307-1318.

91. Winter, K.; Cats, O.; Martens, K.; van Arem, B. Relocating shared automated vehicles under parking constraints: Assessing the impact of different strategies for on-street parking. Transportation 2020, 1-35. [CrossRef]

92. International Transport Forum. Urban Mobility System Upgrade: How Shared Self-Driving Cars Could Change City Traffic; International Transport Forum: Paris, France, 2015.

93. Litman, T. Autonomous Vehicle Implementation Predictions; Victoria Transport Policy Institute: Victoria, BC, Canada, 2014.

94. Bansal, P.; Kockelman, K.M. Forecasting Americans' long-term adoption of connected and autonomous vehicle technologies. Transp. Res. Part A 2017, 95, 49-63. [CrossRef]

95. Deloitte. Gearing for Change: Preparing for Transformation in the Automotive Ecosystem. Available online: https://www2 .deloitte.com/us/en/insights/focus/future-of-mobility/future-of-mobility-transformation-in-automotive-ecosystem.html (accessed on 13 March 2021).

96. The Economist. The Driverless, Car-Sharing Road Ahead. Available online: http://stcwa.org.au/2016/10/the-driverless-carsharing-road-ahead/ (accessed on 13 March 2021).

97. UNCSD. Indicators of Sustainable Development: Framework and Methodologies; United Nations: New York, NY, USA, 1996.

98. EEA. Environmental Indicators: Typology and Overview, Technical Report; EEA: Copenhagen, Denmark, 1999.

99. OECD. OECD Core Set of Indicators for Environmental Performance Reviews; OECD: Paris, France, 1993.

100. Maurya, R.K.; Kulkarni, S.T. Multidimensional spatial clustering and visualization of 3D topographic relief data. Int. J. Inf. Technol. 2021, 1-12. [CrossRef]

101. Kingsley, J.; Egerer, M.; Nuttman, S.; Keniger, L.; Pettitt, P.; Frantzeskaki, N.; Gray, T.; Ossola, A.; Lin, B.; Bailey, A.; et al. Urban agriculture as a nature-based solution to address socio-ecological challenges in Australian. Urban For. Urban Green. 2021, 60, 127059. [CrossRef]

102. Langemeyer, J.; Madrid-Lopez, C.; Beltran, A.M.; Mendez, G.V. Urban agriculture-A necessary pathway towards urban resilience and global sustainability? Landsc. Urban Plan. 2021, 210, 104055. [CrossRef]

103. Whitehead, B.; Andrews, D.; Shah, A.; Maidment, G. Assessing the environment impact of data centres part 1: Background, energy use and metrics. Build. Environ. 2014, 82, 151-159. [CrossRef] 
104. Niaros, V.; Kostakis, V.; Drechsler, W. Making (in) the smart city: The emergence of makerspaces. Telemat. Inform. 2017, 34, 1143-1152. [CrossRef]

105. Kazimieras Zavadskas, E.; Antucheviciene, J.; Kar, S. Multi-Objective and Multi-Attribute Optimization for Sustainable Development Decision Aiding. Sustainability 2019, 11, 3069. [CrossRef]

106. Chen, P. Effects of the entropy weight on TOPSIS. Expert. Syst. Appl. 2021, 168, 114186. [CrossRef]

107. Yu, D.; Pan, T. Tracing knowledge diffusion of TOPSIS: A historical perspective from citation network. Expert. Syst. Appl. 2021, 168, 114238. [CrossRef]

108. Rezaeiha, A.; Montazeri, H.; Blocken, B. A framework for preliminary large-scale urban wind energy potential assessment: Roof-mounted wind turbines. Energ. Convers. Manag. 2020, 214, 112770. [CrossRef]

109. Qu, Y.; Jiang, G.; Li, Z.; Shang, R.; Zhou, D. Understanding the multidimensional morphological characteristics of urban idle land: Stage, subject, and spatial heterogeneity. Cities 2020, 97, 102492. [CrossRef]

110. Lynch, K. The Image of the City; The MIT Press: Cambridge, MA, USA, 1960.

111. Zhang, L.; Peng, Z. Planning and maintenance of urban architectural environmental color-A case study of Xingning Traditional block of Nanning City. Int. J. Electr. Eng. Educ. 2021, in press. [CrossRef]

112. Zheng, C.; Yuan, J.; Zhu, L.; Zhang, Y.; Shao, Q. From digital to sustainable: A scientometric review of smart city literature between 1990 and 2019. J. Clean. Prod. 2020, 258, 120689. [CrossRef]

113. Mitchell, W.J. City of Bits: Space, Place, and the Infobahn; The MIT Press: Cambridge, MA, USA, 1996.

114. United States Environmental Protection Agency. Smart Growth, Brownfields, and Infill Development. Available online: https: / / www.epa.gov/smartgrowth/smart-growth-brownfields-and-infill-development (accessed on 13 March 2021).

115. Wang, Y.; Wang, Y.; Wu, X.; Li, J. Exploring the Risk Factors of Infrastructure PPP Projects for Sustainable Delivery: A Social Network Perspective. Sustainability 2020, 12, 4152. [CrossRef]

116. Zhuang, T.; Qian, Q.K.; Visscher, H.J.; Elsinga, M.G. Stakeholders' Expectations in Urban Renewal Projects in China: A Key Step towards Sustainability. Sustainability 2017, 9, 1640. [CrossRef]

117. Yi, Z.; Liu, G.; Lang, W.; Shrestha, A.; Martek, I. Strategic Approaches to Sustainable Urban Renewal in Developing Countries: A Case Study of Shenzhen, China. Sustainability 2017, 9, 1460. [CrossRef]

118. Liu, G.; Yi, Z.; Zhang, X.; Shrestha, A.; Martek, I.; Wei, L. An Evaluation of Urban Renewal Policies of Shenzhen, China. Sustainability 2017, 9, 1001. [CrossRef]

119. Liu, S.; Zou, G.; Zhang, S. A clustering-based method of typical architectural case mining for architectural innovation. J. Asian Arch. Build. 2020, 19, 71-89. [CrossRef]

120. ArchDaily. Available online: https:/ / www.archdaily.com/ (accessed on 13 March 2021).

121. ArchRecord. Available online: https:/ / www.architecturalrecord.com/ (accessed on 13 March 2021).

122. Guo, Q.; Zou, G. Prediction methods for extension architecture programming based on decision tree classification. CAAI Trans. Intell. Syst. 2017, 12, 117-123. [CrossRef] 